\title{
ANALISA NET PROFIT MARGIN PEDAGANG SAYUR DAN UMBI-UMBIAN DI TANAH PAPUA
}

\author{
SARAH USMAN \\ Fakultas Ekonomi dan Bisnis, Universitas Papua, Manokwari
}

Manokwari peoples activities and papua generally is simple. Local people in their daily activities engage in activities to meet their daily needs, by doing work that is close to the culture of the local community. Sale activities of self-managed garden products can be seen in traditional markets, or along the roads outside of Manokwari. Extensive agricultural land and mixed with the fertile land of Papua, making crops of local communities fertile and can have economic value that can use to local communities daily needs, whether the result of the garden is their consumption or to sale. Seen from the land and profession of most indigenous Papuans is gardening. So the activity of papua people is bringing garden product to the market for sale and gets income. The purpose of research is to find out how much the product cost, how big the results of sales, how big Net Income and how much Net profit margin. Sample Method in this study is simple random sampling where 15 respondents of local traders who are in Sanggeng traditional markets and 15 respondents traders in Wosi traditional market taken with random. Data is taken based on interviews with questionnaire. Questionnaire contains data requirement from respondent that is income and cost. the data analysis method is Profitability with Net profit margin Analysis. Net profit margin is $69.2 \%$ means that the profit generated is $69.2 \%$ of the overall sales, every month every trader. This is because that $30.8 \%$ is all cost used of the total sales. Result of the Net profit margin means that the business of trading vegetables and tubers is potentially to increase income for the papua people.

Keywords: Profit, Income, Local Trader, Manokwari, West papua 


\section{PENDAHULUAN}

Hasil pertanian dan perkebunan masyarakat Papua barat menjadi sektor utama perekonomian masyarakat, dimana hasil pertanian diperdagangkan dipasar tradisional. Disebagian besar provinsi, pasar merupakan tempat stategis untuk melakukan aktivitas perdagangan. Pasar merupakan ruang sosial di samping ruang ekonomi, yang dapat diartikan bahwa pasar berkembang berdampingan bersama sektor ekonomi. Pasar tradisional merupakan tempat melakukan aktivitas perdagangan yang telah dikenal masyarakat indonesia sejak lama. Aktivitas berdagang dipasar tradisional tidak asing bagi masyarakat Papua, yang terkenal dengan luas lahan dan hasil tanaman yang beragam.

Aktivitas masyarakat di manokwari dan Papua umumnya lebih sederhana, dimana masyarakat lokal dalam keseharian melakukan aktivitas untuk memenuhi kebutuhan hidup sehari-hari, dengan melakukan pekerjaan yang dekat dengan budaya masyarakat lokal. Aktivitas berdagang hasil kebun yang dikelolah sendiri bisa terlihat dipasar-pasar tradisional, ataupun di sepanjang jalan menuju luar manokwari. Lahan pertanian yang luas dan dipadupadankan dengan suburnya tanah Papua, membuat hasil tanaman masyarakat lokal subur dan bisa mempunyai nilai ekonomis yang dapat membiayai kebutuhan sehari-hari masyarakat lokal. Baik hasil itu di konsumsi sendiri ataupun diperdagangkan. Terlihat dari luas lahan dan profesi sebagian besar masyarakat asli Papua yaitu berkebun. Maka aktivitas berdagang masyarakat yaitu membawa hasil lahannya ke pasar untuk dijual dan memperoleh pendapatan.

\section{Rumusan Masalah}

Berdasarkan latar belakang diatas maka dapat dirumuskan masalah, sebagai berikut:

- Seberapa besar biaya yang dikeluarkan oleh pedagang?

- Seberapa besar penerimaan pedagang?

- Seberapa besar Net Income pedagang?

- Seberapa besar Net profit margin pedagang?

\section{Tujuan penelitian}

Adapun tujuan dalam penelitian ini, adalah :

- Untuk mengetahui seberapa besar biaya yang dikeluarkan oleh pedagang.

- Untuk mengetahui seberapa besar hasil penjualan pedagang.

- Untuk mengetahui seberapa besar Net Income pedagang.

- Untuk mengetahui seberapa besar Net profit margin pedagang.

\section{TINJAUAN PUSTAKA}

\section{Pendapatan}

Pendapatan menurut Zaki Baridwan (1992) menyatakan bahwa: "Pendapatan (revenue) adalah aliran masuk atau kenaikan lain aktiva suatu badan usaha atau pelunasan utangnya (atau kombinasi keduanya) selama satu periode yang berasal dari penyerahan atau pembuatan barang, penyerahan jasa, atau dari kegiatan lain yang merupakan kegiatan utama badan usaha". BPS (2014) memberikan pengertian pendapatan yang digolongkan menjadi tiga, yaitu sebagai berikut:

1. Pendapatan berupa uang, yaitu sebagai penghasilan berupa uang yang sifatnya regular dan biasanya diterima sebagai balas jasa atau kontraprestasi yang meliputi:

a. Gaji dan upah yang diperoleh dari kerja pokok, kerja lembur, kerja sampingan dan kerja kadang-kadang.

b. Pendapatan dari usaha sendiri yang meliputi hasil bersih usaha sendiri, konsumsi dan penjualan dari kerajinan rumah tangga.

c. Pendapatan dari hasil investasi seperti bunga, modal dan tanah.

d. Pendapatan dari keuntungan sosial (dari kerja sosial)

2. Pendapatan berupa barang, adalah sebagai penghasilan yang sifatnya reguler akan tetapi tidak selalu berbentuk balas jasa yang diterima dalam bentuk barang dan jasa. Barang atau jasa yang diperoleh dinilai dengan harga pasar sekalipun tidak disertai transaksi uang oleh yang menikmati barang atau jaa tersebut.

3. Penerimaan yang bukan merupakan pendapatan, yaitu penerimaan yang berupa pengambilan tabungan, penjualan barang-barang yang dipakai, pinjaman uang, hadiah, warisan dan sebagainya. 
Pendapatan adalah peningkatan jumlah aktiva atau penurunan jumlah kewajiban suatu badan usaha yang timbul dari penyerahaan barang dan jasa atau aktifitas usaha yang lainnya dalam suatu periode. (IAI:1997). Sedangkan, menurut Sumardi, (1982) Pendapatan adalah pendapatan uang yang diterima dan diberikan kepada subjek ekonomi berdasarkan prestasi-prestasi yang diserahkan yaitu berupa pendapatan dari profesi yang dilakukan sendiri atau usaha perorangan dan pendapatan dari kekayaan.

\section{Net profit margin}

Menurut Bastian dan Suhardjono (2006), Net profit margin adalah perbandingan antara laba bersih dengan penjualan. Rasio ini sangat penting bagi manajer operasi karena mencerminkan strategi penetapan harga penjualan yang diterapkan perusahaan dan kemampuannya untuk mengendalikan beban usaha. Net Profit Margin merupakan rasio antara laba bersih (net profit) yaitu sesudah dikurangi dengan seluruh expenses termasuk pajak dibandingkan dengan penjualan (Syamsuddin, 2007). Menurut Astuti (2005 dalam kumalasari (2016) bahwa Keuntungan (laba) adalah perbedaan antara penghasilan dan biaya yang dikeluarkan.

\section{Penelitian terdahulu}

Rizky Andarways Kumalasari (2016) “Analisis Keuntungan Pedagang Nasi Kuning (Studi Kasus Pedagang Nasi Kuning di Pasar Palaran Kecamatan Palaran Kota Samarinda). Tujuan dari Penelitian ini adalah untuk mengetahui dan menganalisis besarnya keuntungan rata-rata yang diperoleh dari usaha pedagang nasi kuning di pasar palaran dan sebagai informasi yang berguna bagi pelaku usaha dalam mengelola dan meningkatkan keuntungan dalam usahanya. Analisis yang digunakan adalah Analisis Penerimaan, Analisis Total Biaya, Analisis R/C Rasio. Hasil penelitian, sebanyak 7 Responden, keseluruhan memiliki tingakat imbangan atas R/C Rasio >1,21 yang berarti bahwa usaha tersebut layak atau termasuk ke dalam kriteria tingkat $\mathrm{R} / \mathrm{C}$ tinggi.

Nicolas Butarbutar, dkk (2014) “Analisis keuntungan pedagang pengecer daging sapi di pasar tradisional kota Manado". Tujuan penelitian untuk mengetahui berapa besar penggunaan biaya operasional dan keuntungan yang diterima. sampel dilakukan secara purposive sampling. Hasil penelitian bahwa rata-rata biaya operasional yang digunakan pedagang pengecer dalam pemasaran daging sapi sebesar Rp.60.000.258 perminggu atau sebesar Rp.239.990.725 perbulan. Besarnya keuntungan yang diterima pedagang pengecer daging sapi yaitu rata-rata Rp.3.703.093 perminggu atau sebesar Rp.14.822.681 perbulan.

Priska Sigarlaki, dkk (2014), Analisis Net Profit Margin Pada Perusahaan Depot Air Minum Di Lingkungan Kampus Universitas Sam Ratulangi. Net Profit Margin (NPM) merupakan satu indikator penting dalam mencapai tujuan perusahaan yang bermanfaat untuk menyediakan informasi bagi manajemen perusahaan mengenai efisiensi perusahaan berdasarkan perhitungan yang membandingkan antara laba bersih dan penjualan bersih. penelitian ini bertujuan untuk menganalisis NPM pada usaha depot air minum. Hasil penelitian menunjukan bahwa Depot Water memiliki kemampuan memperoleh laba lebih tinggi dibandingkan dengan depot Scarlet dan Michelle, dan perhitungan NPM belum menunjang kinerja ketiga depot yang bersangkutan.

\section{METODE PENELITIAN}

\section{Sampel}

Sampel menurut Sugiyono (2009) adalah bagian dari populasi yang akan dijadikan responden untuk menggambarkan kondisi populasi yang akan diteliti berdasarkan fakta dan data. Metode Sampel dalam penelitian ini adalah simple random sampling terhadap pedagang lokal manokwari dengan produk yang dijual adalah sayur-mayur dan umbi-umbian. Jumlah 30 responden diperoleh dari 15 responden pedagang lokal yang berada di pasar tradisional sanggeng dan 15 responden pedagang di pasar wosi di ambil secara acak.

\section{Data}

Data dalam penelitian ini adalah data primer merupakan sumber data penelitian yang diperoleh secara langsung dari sumber asli (tidak melalui perantara). Data primer secara khusus dikumpulkan oleh peneliti untuk menjawab pertanyaan pe- 
nelitian (Indriantoro, 1999). Dalam penelitian ini data diambil berdasarkan wawancara dengan panduan pertanyaan berupa angket. Angket berisi kebutuhan data dari responden, yaitu data pendapatan dan alokasi penggunaan pendapatan tersebut.

\section{Operasionalisasi Variabel}

Penelitian ini menggunakan Analisa Profitabilitas Keuangan yaitu

1. Net profit margin merupakan perbandingan nilai bersih dari pendapatan dilihat dari total penjualan yang diperoleh, dengan rumus:

\section{$N P M=$ Net Income $:$ Net sale $x 100$}

2. Net Income merupakan pendapatan bersih dari penjualan setelah dikurangi biaya-biaya, dirumuskan sebagai berikut:

\section{Net Income $=$ Total revenue - Total Cost}

\section{Metode Analisis}

Penelitian ini menggunakan analisis keuangan dengan model persamaan sebagai berikut:

1. Akumulasi biaya operasional yang dikeluarkan oleh pedagang.

2. Akumulasi penerimaan dari penjualan pedagang.

3. Net Income dari penjualan menurut Soekartawi (2003) dalam kumalasari (2016), formulasi adalah:

\section{Net Income $(\pi)=T R-T C$}

Dimana :

Net Income = Keuntungan / Laba bersih $\mathrm{TR}=$ Total Revenue (Total Penerimaan $)$ $\mathrm{TC}=$ Total Cost (Total Biaya)

4. Net profit margin pedagang menurut Harahap (2007), formulasi sebagai berikut:

$$
N P M=(\text { Net Income/Net Sales }) \times 100
$$

Dimana:

Net Income $=$ Laba bersih

Net Sales $=$ Penjualan bersih

\section{HASIL DAN PEMBAHASAN}

\section{Biaya Operasional Pedagang}

Hasil penelitian yang dilakukan untuk mengetahui total biaya yang dikeluarkan oleh pedagang dalam rangka memenuhi kegiatan operasional berkaitan produk dagangan pada pedagang sayur dan umbi-umbian pasar tradisional.

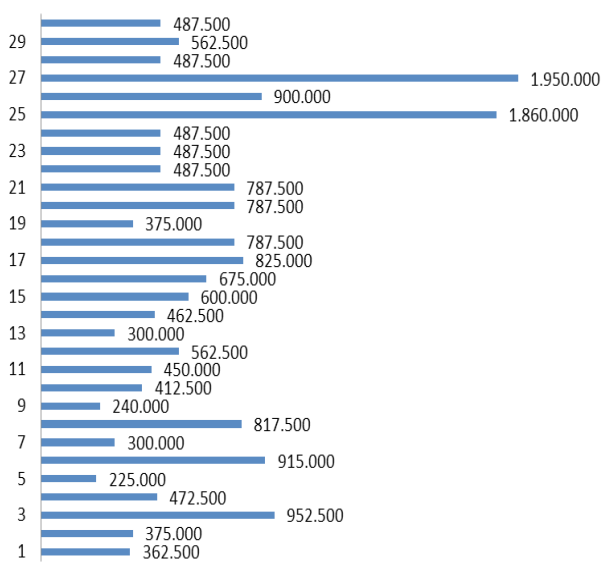

Gambar 1. Biaya operasional pedagang

Berdasarkan gambar 1 terlihat bahwa setiap bulannya biaya tertinggi yang dikeluarkan sebesar Rp. 1.950.000 dan terendah sebesar Rp.225.000. Jika di rata-ratakan maka pengeluaran biaya operasional sebesar Rp. 646.500. biaya operasional yang dikeluarkan meliputi biaya bahan baku baik yang merupakan hasil tanam ataupun dibeli, biaya transportasi menuju dan balik lokasi pasar, serta kebutuhan dalam melakukan proses perdagangan.

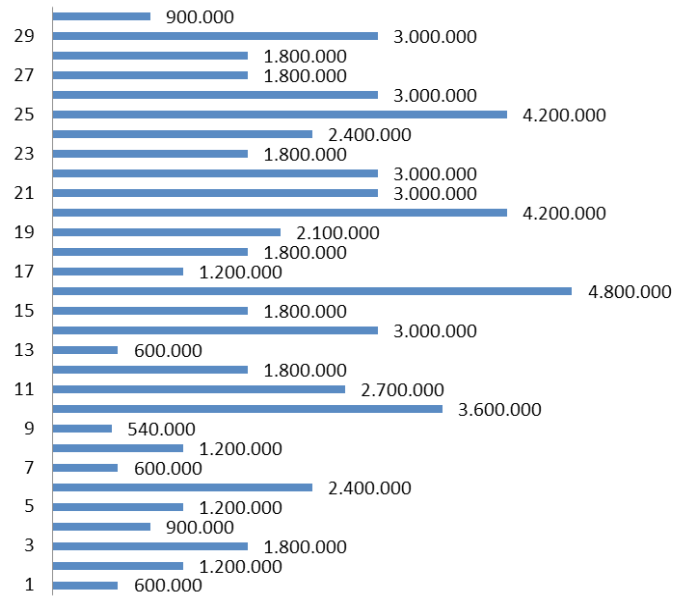

Gambar 2. Penerimaan Hasil Dagangan 


\section{Penerimaan Pedagang}

Seperti yang digambarkan pada Gambar 2 terlihat bahwa penerimaan pedagang lokal setiap bulan, tertinggi sebesar Rp.4.800.000 dan terendah sebesar Rp. 540.000. jika di rata-ratakan maka total penerimaan sebesar Rp. 2.098.000.

\section{Net Income Pedagang}

Berdasarkan Gambar 3 terlihat bahwa, dari 30 responden yang ditemui sebagian besar mendapatkan Net Income dari usaha berdagang, 1 responden yang mengalami kerugian. Nilai Net Income tertinggi sebesar Rp.4.125.000 dan terendah sebesar Rp.(150.000).-. jika di rata-ratakan maka besarnya Net Income yang dimiliki oleh pedagang adalah sebesar Rp. 1.451.500.- setiap bulan setiap pedagang.

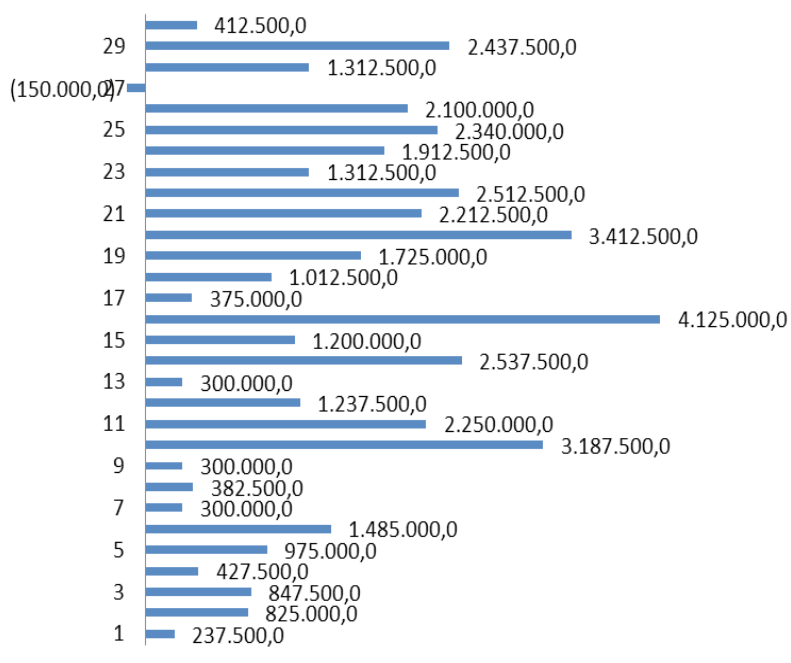

Gambar 3. Net Income (laba) Pedagang

\section{Net profit margin pedagang}

Hasil Net profit margin pedagang lokal manokwari seperti terlihat pada Gambar 4 bahwa Net profit margin tertinggi sebesar $88,5 \%$ dan terendah sebesar $(8,3) \%$. Jika dirata-ratakan maka besarnya Net profit margin adalah 69,2\%. Artinya laba yang di hasilkan adalah 69,2\% dari keseluruhan penjualan yang dilakukan setiap bulan setiap pedagang.

Nilai Net profit margin yang dihasilkan, maka usaha berdagang sayur dan umbi-umbian berpotensi meningkatkan pendapatan masyarakat papua khususnya. Hal ini di sebabkan oleh biaya operasional yang dikeluarkan sebesar 30,8\% dari total penjualan, dimana sebagian besar responden memperoleh bahan baku dengan biaya kecil yaitu Rp.1.012.000 setiap bulan sebelum di jual ke pasar.

Harga jual yang di berikan sama oleh setiap pedagang yang membeli bahan baku atau tidak membeli karena bahan baku sayur dan umbi-umbian tumbuh subur di lahan pribadi tanpa perawatan yang memerlukan biaya besar. Harga yang diberikan yaitu sebesar Rp.5.000 perikat bagi sayur dan Rp.20.000 per tumpuk bagi umbi-umbian dengan rata-rata hasil terjual $168 \mathrm{ikat} /$ tumpuk setiap bulan atau rata-rata $6 \mathrm{ikat} /$ tumpuk setiap hari.

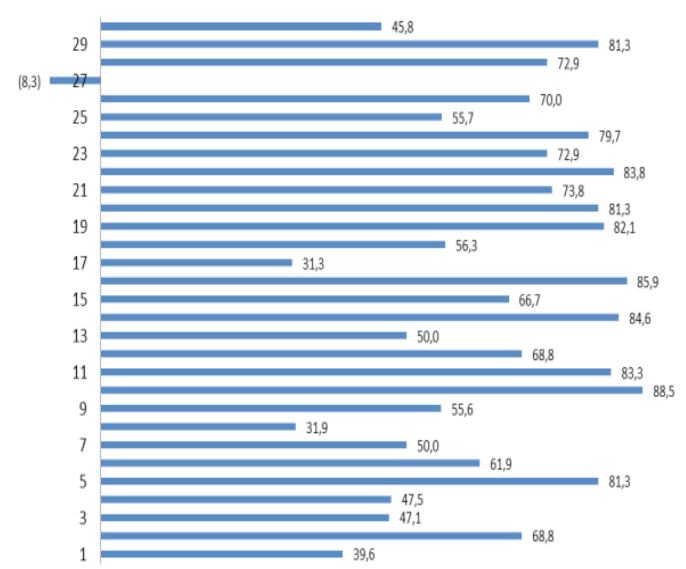

Gambar 4. Net profit margin Pedagang

\section{KESIMPULAN}

Setelah dilakukan analisis data dalam penelitian ini, maka dapat diambil beberapa kesimpulan yaitu besarnya Net profit margin adalah 69,2\%. Artinya laba yang di hasilkan adalah $69,2 \%$ dari keseluruhan penjualan yang dilakukan setiap bulan setiap pedagang. Artinya biaya operasional yang dikeluarkan sebesar $30,8 \%$ dari total penjualan. Dengan nilai Net profit margin yang dihasilkan, maka usaha berdagang sayur dan umbiumbian berpotensi meningkatkan pendapatan masyarakat papua khususnya.

\section{SARAN}

Penelitian selanjutnya diharapkan dapat melakukan analisa yang lebih dalam dan menggelompokkan pedagang secara terpisah berdasarkan produk yang di perdagangkan. 


\section{REFERENSI}

Badan Pusat Satistik (BPS). 2014. Daerah dalam angka (DDA). BPS Provinsi Papua Barat.

Baridwan, Zaki. 1992. Intermediate accounting, edisi: 7. Yogyakarta: Fakultas Ekonomi Universitas Atma Jaya.

Bastian, Indra dan Suhardjono. 2006. Akuntansi Perbankan. Edisi 1. Jakarta: Salemba Empat.

Harahap, Sofyan Syahfri. 2007. Analisis Kritis atas Laporan Keuangan. PT. Raja Grafindo Persada. Jakarta.

Ikatan Akuntan Indonesia. 1997. Prinsip Akuntansi Indonesia.. Penerbit: Rineka Cipta. Jakarta.

Indiantoro nur, Bambang supomo. 1999. Metodologi Penelitian Bisnis. BPFE Yogyakarta.

Kumalasari Andarways Rizky. 2016. Analisis Keuntungan Pedagang Nasi Kuning ( Studi Kasus Pedagang Nasi Kuning di Pasar Palaran Kecamatan Palaran Kota Samarinda ). eJournal Administrasi Bisnis, ISSN 2355-5408 hal 990-1001.

Nicolas Butarbutar, dkk. 2014. Analisis Keuntungan Pedagang Pengecer Daging Sapi Di Pasar Tradisional Kota Manado. Jurnal Zootek (“Zootrek” Journal) Vol 34 No. 1:48-61 ISSN 0852 -2626.

Priska Sigarlaki, dkk. 2014. Analisis Net Profit Margin Pada Perusahaan Depot Air Minum Di Lingkungan Kampus Universitas Sam Ratulangi. Jurnal EMBA, Vol.2 No.2 Juni 2014. ISSN 2303-1174. Hal 1617-1627

Sugiyono.2009. Metode Penelitian pendidikan. Penerbit : ALFABETA, Bandung.

Sumardi, Mulyanto dan Hans Dieters Evers. 1982. Kemiskinan dan Kebutuhan Pokok. Jakarta : Rajawali.

Syamsuddin, Lukman. 2007. Manajemen Keuangan Perusahaan: Konsep Aplikasi dalam Perencanaan, Pengawasan, dan pengambilan Keputusan (Edisi Baru). Jakarta: PT. Raja Grafindo Persada. 